\title{
Persepsi Pelaku Utama terhadap Pengembangan Budidaya Ikan Air Payau Ramah Lingkungan di Wilayah Pesisir (Kasus Di Kabupaten Serang - Banten)
}

\author{
[Perception Of Fishermen For Brackish Water Development On Coastal Friendly Environment \\ Eco-Shrimp \\ (Case Research In District Of Serang Banten - West Java) \\ Ani Leilani ${ }^{\bowtie}$, Ina Restuwati, Muh.Patekkai \\ Sekolah Tinggi Perikanan, Jurusan Penyuluhan Perikanan \\ Jalan Cikaret Nomor 1 Bogor 16001, Jawa Barat \\ Diterima: 28 Mei 2015; Disetujui: 11 November 2015
}

\begin{abstract}
Abstrak
Penelitian ini bertujuan untuk mengidentifikasi karakteristik pelaku utama (nelayan) yang berhubungan nyata dengan persepsi lingkungan pesisir; faktor lingkungan pesisir yang berhubungan nyata dengan persepsi lingkungan pesisir; menganalisis faktor-faktor karakteristik pelaku utama (nelayan) dan faktor lingkungan pesisir yang berhubungan signifikan dengan persepsi lingkungan pesisir. Manfaat penelitian untuk mengetahui persepsi pelaku utama perikanan terhadap lingkungan perairan air payau dalam hubungannya dengan budidaya ramah lingkungan (Eco-Shrimp) dan memperoleh analisis tentang faktor-faktor yang terkait dengan internal dan eksternal pembudidaya ikan di perairan payau di Kabupaten Serang yang dapat dijadikan acuan dalam pelaksanaan budidaya air payau ramah lingkungan. Responden sebanyak 40 (empat puluh) orang pelaku utama perikanan di wilayah pesisir Kabupaten Serang tepatnya di Kelurahan Menggerong Kecamatan Kasemen. Data dianalisis menggunakan uji korelasi Rank Spearman. Hasil distribusi karakteristik pelaku utama disimpulkan bahwa tingkat kekosmopolitan pelaku utama (nelayan) berkorelasi langsung pada persepsi mereka terhadap lingkungan pesisir dengan besaran (rs) keselarasan/ kompatibilitas sebesar .537**, kompleksitas/kerumitan sebesar $.572 * *$, trial ability/dapat dicoba $.430 * *$ dan observability/dapat diamati sebesar $.530^{* *}$. Hasil uji Korelasi Rank Spearman menunjukkan bahwa variabel faktor lingkungan pesisir yang sangat signifikan berhubungan dengan persepsi lingkungan pesisir adalah variabel kondisi alam, interaksi sosial, budaya dan kondisi ekonomi, sedangkan perilaku masyarakat tidak berhubungan secara signifikan.
\end{abstract}

Kata penting : persepsi, karakteristik pelaku utama, lingkungan pesisir, eco-shrimp 


\begin{abstract}
This research aims to identify the characteristics of fishermen as main actors which are significantly related to coastal environmental perceptions; identify coastal environmental factors that are significantly related to coastal environmental perceptions; analyzing the characteristics of the main actors and coastal environmental factors that are significantly related to the perception of the coastal environment. The research wants to know that the main actors perception on brackish water environment in relation to eco-shrimp and obtain the analysis of related factors to internal and external fish farmers. That can be used as a reference in the implementation of brackish water cultivation environmentally friendly. Respondents of this research are 40 (forty) main actors of fisheries in coastal area of Menggerong Village Kasemen District of Serang Regency. Data are analyzed using Rank Spearman correlation test. The main actors distribution results concluded that the cosmopolitan level of the main actors directly correlated to their perception of the coastal environment with the amount of (rs) alignment / compatibility of $.537 * *$, complexity of $.572 * *$, trial ability of $.430^{* *}$ and observability of $.530^{* *}$. The result of Spearman Rank correlation test showed that the variables of coastal environmental factors which are very significant related to the perception of coastal environment are natural condition variable, social interaction, culture and economic condition, whereas community behavior is not related significantly.
\end{abstract}

Keywords: perception, characteristics of main actors, coastal environment, eco-shrimp.

$\triangle$ Penulis korespondensi

Alamat surel: anileilani@gmail.com; restuina@gmail.com; patekkaimuhammad@gmail.com

\section{PENDAHULUAN}

Indonesia diberi julukan sebagai negara maritim, selain luas laut yang dimiliki sekitar dua pertiga dari luas wilayahnya, Indonesia juga merupakan negara kepulauan, dengan panjang pantai $\pm 81.000 \mathrm{~km}$, dan sumberdaya pesisir yang melimpah ruah. Umumnya wilayah pesisirnya mempunyai ekosistem yang sangat beraneka ragam, antara lain hutan mangrove, terumbu karang, padang lamun, serta rumput laut.

Laut memiliki banyak fungsi, peran serta manfaat bagi kehidupan manusia dan makhluk hidup lainnya karena di dalam dan di atas laut terdapat kekayaan sumber daya alam yang dapat kita manfaatkan diantaranya yaitu sebagai tempat hidup sumber makanan manusia, tempat budidaya ikan, kerang mutiara, rumput laut, tempat hiburan 
atau rekreasi, serta tempat barang tambang berada dan juga sebagai jalur transportasi air.

Saat ini, wilayah pesisir telah menjadi lokasi yang sangat dimanfaatkan oleh manusia untuk menjalankan aktifitasnya seperti budidaya perikanan, konservasi dan pemukiman bagi masyarakat pesisir. Dengan ekploitasi sumberdaya pesisir yang cukup besar saat ini, perlu kiranya diketahui tentang sudut pandang masyarakat tentang wilayah pesisir. Sudut pandang ini yang nantinya akan menjadi tolak ukur bagaimana masyarakat memberikan persepsi kepada lingkungan pesisir yang saat ini tengah dimanfaatkan untuk kegiatan perikanan.

Sumberdaya pesisir dan kelautan terus mengalami penurunan di seluruh dunia, meningkatkan ancaman terhadap manusia dan komunitas alam lainnya. Lebih buruknya, ilmuwan setuju bahwa perubahan iklim akan membuat konservasi laut lebih sulit di masa depan. Masalah ini sangat akut bagi terumbu karang dan ekosistem lainnya yang sangat terancam. Kenyataan yang tidak enak adalah bahwa status quo pendekatan "lebih daripada sama" sepertinya tidak berhasil dalam melindungi sumberdaya kelautan yang berada dalam kondisi kritis.
Dari kondisi yang kurang bagus tersebut, penulis akan mencoba untuk menganalisa sejauhmana sebenarnya masyarakat pesisir memandang wilayah pesisir tempat mereka bermukim. Perlu adanya suatu penelitian yang dapat memberikan informasi tentang sudut pandang masyarakat pesisir terhadap tentang wilayahnya yang saat ini menjadi sentra kegiatan perikanan khususnya budidaya perikanan.

Sehubungan dengan hal tersebut, masalah penelitian (research question) yang ingin dijawab dari penelitian ini adalah: Pertama, bagaimana persepsi pelaku utama perikanan terhadap lingkungan perairan air payau dalam hubungannya dengan budidaya ramah lingkungan (Eco-Shrimp). Kedua, memperoleh analisis tentang faktorfaktor yang terkait dengan karakteristik pembudidaya ikan (pelaku utama) yang dapat dijadikan acuan dalam pelaksanaan budidaya air payau ramah lingkungan. Untuk mengetahui sejauhmana persepsi pelaku utama dilakukan identifikasi tentang: (1) Karakteristik pelaku utama (nelayan) yang berhubungan nyata dengan persepsi lingkungan pesisir; (2) Mengidentifikasi faktor lingkungan pesisir yang berhubungan nyata dengan persepsi lingkungan pesisir dan; (3) Menganalisis faktor-faktor karakteristik 
pelaku utama (nelayan) dan faktor lingkungan pesisir yang berhubungan signifikan dengan persepsi lingkungan pesisir.

\section{HASIL DAN PEMBAHASAN}

\section{Karakteristik Individu Pelaku Utama (Nelayan)}

Karakteristik nelayan adalah ciriciri atau sifat yang melekat pada diri nelayan sebagai pelaku utama perikanan. Karakteristik nelayan yang diamati dalam penelitian ini adalah umur, tingkat pendidikan formal, pengalaman dan minat, serta tingkat kekosmopolitan. Distribusi responden berdasarkan karakteristik pelaku utama dalam penelitian ini dijelaskan sebagai berikut : Distribusi Nelayan Berdasarkan Umur
Umur yang dimaksudkan dalam penelitian ini adalah lamanya hidup nelayan yang dihitung dalam tahun sejak ia dilahirkan sampai dengan saat penelitian ini dilakukan. Kategori muda adalah umur 19 s/d 35 tahun, sedang berkisar 36 s/d 50 tahun, dan kategori tua dengan umur $\geq 51$ tahun. Dari 40 rsponden sebanyak 57 persen berumur muda, 30 persen berumur sedang, dan selebihnya 13 persen nelayan berumur tua.

Distribusi Nelayan Berdasarkan Tingkat Pendidikan Formal

Jenjang pendidikan yang dimaksudkan dalam penelitian ini adalah tingkat pendidikan formal terakhir nelayan yang diselesaikan dengan memperoleh ijazah hingga

Tabel 1. Rekapitulasi Distribusi Karakteristik Nelayan

\begin{tabular}{lccc}
\hline Karakteristik Nelayan & Kategori & $\begin{array}{c}\text { Frekuensi } \\
\text { (n) }\end{array}$ & $\begin{array}{c}\text { Persentase } \\
\text { (\%) }\end{array}$ \\
\hline Umur & Muda (19-35 tahun) & 23 & 57 \\
(rataan umur 35 tahun) & Sedang (36-50 & 12 & \\
& tahun) & & 30 \\
Tingkat pendidikan & Tua $\geq 51$ tahun) & 15 & 13 \\
formal (rataan SD) & Rendah ( SD ) & 21 & 52 \\
& Sedang (SLTP) & 10 & 25 \\
& Tinggi (SLTA) & 9 & 23 \\
Pengalaman usaha dan & Rendah (1-5 tahun) & 26 & 65 \\
Minat (Rataan 5 tahun) & Sedang (6-10 tahun) & 8 & 20 \\
Tingkat kekosmopolitan & Tinggi (11-16 tahun) & 6 & 15 \\
(rataan skor 2) & Rendah (skor 1) & 12 & 30 \\
& Sedang (skor 2) & 27 & 68 \\
& Tinggi (skor 3) & 1 & 2 \\
\hline
\end{tabular}

Keterangan: $n=40$. 
Tabel 2. Rekapitulasi Distribusi Faktor Lingkungan Pesisir

\begin{tabular}{lccc}
\hline Faktor Lingkungan Pesisir & Kategori & $\begin{array}{c}\text { Frekuensi } \\
\text { (n) }\end{array}$ & $\begin{array}{c}\text { Persentase } \\
\text { (\%) }\end{array}$ \\
\hline Kondisi Alam & & 25 & 63 \\
(Rataan Skor 1) & Rendah (skor 1) & 9 & 22 \\
& Sedang (skor 2) & 6 & 15 \\
Interaksi Sosial & Tinggi (skor 3) & 11 & 27 \\
(Rataan Skor 2) & Rendah (skor 1) & 24 & 60 \\
& Sedang (skor 2) & 5 & 13 \\
Faktor Budaya (Rataan Skor & Tinggi (skor 3) & 14 & 36 \\
1) & Rendah (skor 1) & 13 & 32 \\
& Sedang (skor 2) & 13 & 32 \\
Falktor Perilaku Masyarakat & Tinggi (skor 3) & 24 & 60 \\
(Rataan Skor 1) & Rendah (skor 1) & 13 & 32 \\
& Sedang (skor 2) & 3 & 8 \\
Faktor Kondisi Alam & Tinggi (skor 3) & 21 & 53 \\
(Rataan Skor 1) & Rendah (skor 1) & 17 & 42 \\
& Sedang (skor 2) & 2 & 5 \\
\hline Keterangan: & Tinggi (skor 3) & &
\end{tabular}

dilaksanakannya penelitian. Jenjang pendidikan dibagi dalam tiga kategori yakni rendah ialah SD, kategori sedang dengan jenjang SLTP, dan SLTA termasuk kategori tinggi.. Hasil distribusi menghasilkan data dari 40 responden, sebanyak 52 persen nelayan berpendidikan SD, 25 persen berpendidikan SLTP dan selebihnya 23 persen nelayan berpendidikan SLTA. Dengan demikian hasil penelitian mengungkapkan bahwa sebagian besar responden memiliki tingkat pendidikan SD yaitu sebanyak 21 orang.

\section{Distribusi Nelayan Berdasarkan Pengalaman Usaha dan Minat}

Distribusi nelayan berdasarkan pengalaman usaha dan minat adalah berapa lama nelayan responden melakukan usaha penangkapan ikan dan Volume 9 Nomor 2, Desember 2015 melakukan usaha lainnya yang mendukung usaha penangkapan ikannya. Pengalaman Usaha nelayan responden dibagi ke dalam 3 kategori yaitu kategori rendah (1-5 tahun), kategori sedang (610 tahun) dan kategori tinggi (11-16 tahun). Dari 40 nelayan responden sebanyak 65 persen nelayan mempunyai pengalaman usaha yang rendah, 20 persen mempunyai pengalaman usaha sedang dan sisanya sebesar 15 persen mempunyai pengalaman usaha yang tinggi. Dengan demikian hasil penelitian mengungkapkan bahwa sebagian besar nelayan responden memiliki pengalaman usaha rendah yaitu sebanyak 26 orang atau sebesar 65 persen.

Distribusi Pembudidaya Berdasarkan Tingkat Kekosmopolitan 
Distribusi nelayan berdasarkan tingkat kekosmopolitan adalah merupakan keterbukaan dan upaya nelayan responden untuk selalu berusaha mencari informasi tentang usaha penangkapan yang dilakukannya baik dengan cara berkunjung ke lauar daerah dan bekerjasama dengan kelompok usaha bersama lainnya dalam bidang penangkapan, berkonsultasi dengan PPL di wilayahnya maupun dengan dinas terkait, melakukan tukar menukar informasi dan pengetahuan dengan sesama nelayan di wilayahnya, serta melakukan akses informasi tentang penangkapan ikan melalui radio, televisi, surat kabar dan media lainnya. Tingkat kekosmopolitan nelayan responden dibagi ke dalam 3 kategori yaitu kategori rendah (Skor 1), kategori sedang (Skor 2) dan kategori tinggi (Skor 3). dari 40 nelayan responden sebanyak 30 persen nelayan tingkat kekos-mopolitannya rendah, 68 persen mempunyai tingkat kekosmopolitan sedang dan sisanya sebesar 2 persen dengan tingkat kekosmopolitan rendah. Dengan demikian hasil penelitian mengungkapkan bahwa sebagian besar nelayan responden memiliki tingkat kekosmopolitan yang sedang yaitu sebanyak 27 orang atau sebesar 68 persen.
Dari rekapitulasi distribusi karakteristik pelaku utama di atas kemudian dilakukan analisis hubungan antara karakteristik nelayan dengan persepsi terhadap lingkungan pesisir untuk mengetahui variabel mana saja yang berhubungan secara signifikan dengan persepsi nelayan terhadap lingkungan pesisir. Distribusi karakteristik pelaku utama (nelayan) terdiri dari variabel umur, tingkat pendidikan formal, pengalaman dan minat serta tingkat kekosmopolitan. Setelah dilakukan analisis dengan menggunakan uji korelasi Rank Spearmen terlihat bahwa tingkat kekosmopolitan pelaku utama (nelayan) di Kelurahan Menggerong Kecamatan Kasemen Kabupaten Serang ini berkorelasi signifikan terhadap persepsi terhadap lingkungan pesisir dengan besaran (rs) keselarasan/kompatibilitas sebesar $.537^{* *}$, kompleksitas/kerumitan sebesar $.572 * *$, trial ability/dapat dicoba $.430 * *$ dan observability/dapat diamati sebesar .530**. Dengan demikian terdapat hubungan yang nyata dan sangat signifikan antara karakteristik pelaku utama (nelayan) pada variabel tingkat kekosmopolitan terhadap persepsi lingkungan pesisir, sedangkan umur, tingkat pendidikan formal serta pengalaman dan minat pelaku utama 
(nelayan) tidak berhubungan signifikan dengan persepsi terhadap lingkungan pesisir.

\section{Faktor Kelompok}

Distribusi Kondisi Alam Terhadap Lingkungan Pesisir

Distribusi kondisi alam terhadap lingkungan pesisir dibagi menjadi tiga kategori yaitu rendah, sedang dan tinggi. Kategori rendah dengan skor 1, kategori sedang dengan skor 2, sedangkan kategori tinggi dengan skor 3. Dari jumlah responden sebanyak 40 orang dihasilkan distribusi sebanyak 25 persen dari responden menyatakan bahwa faktor kondisi alam yang berhubungan dengan kondisi alam pesisir masih rendah, 9 persen menyatakan pada kategori sedang, dan selebihnya 6 persen menyatakan mempunyai tinggi. Dengan demikian diketahui bahwa mayoritas responden menyatakan bahwa faktor kondisi alam yang berhubungan dengan lingkungan pesisir masih rendah dengan skor 1 .

$\begin{array}{cc}\begin{array}{l}\text { Distribusi Interaksi Sosial } \\ \text { Lingkungan Pesisir }\end{array} & \\ \text { Distribusi interaksi } & \text { sosial } \\ \text { terhadap lingkungan pesisir } & \text { dibagi } \\ \text { menjadi tiga kategori yaitu rendah, }\end{array}$

sedang dan tinggi. Kategori rendah dengan skor 1, kategori sedang dengan skor 2, sedangkan kategori tinggi dengan skor 3. Dari 40 orang responden sebanyak 11 persen menyatakan bahwa faktor interaksi sosial yang berhubungan dengan kondisi alam pesisir masih rendah, 24 persen menyatakan pada kategori sedang, dan selebihnya 5 persen menyatakan mempunyai kategori yang tinggi.

Distribusi Faktor Budaya Terhadap
Lingkungan Pesisir Distribusi faktor budaya lingkungan pesisir dibagi menjadi tiga kategori yaitu rendah, sedang dan tinggi. Kategori rendah dengan skor 1, kategori sedang dengan skor 2, sedangkan kategori tinggi dengan skor 3. Dari 40 orang responden sebanyak 14 persen menyatakan bahwa faktor budaya yang berhubungan dengan kondisi alam pesisir masih rendah, 13 persen menyatakan pada kategori sedang, dan selebihnya 13 persen menyatakan mempunyai kategori yang tinggi.

Distribusi Faktor Perilaku Masyarakat Terhadap Lingkungan Pesisir 
Tabel 3. Hubungan antara Faktor Lingkungan Pesisir dengan persepsi pelaku utama terhadap lingkungan pesisir.

\begin{tabular}{|c|c|c|c|c|c|}
\hline \multirow[b]{2}{*}{$\begin{array}{c}\text { Faktor } \\
\text { Lingkungan } \\
\text { Pesisir }\end{array}$} & \multicolumn{5}{|c|}{ Persepsi Pelaku Utama Terhadap Lingkungan Pesisir $\left(\mathrm{r}_{\mathrm{s}}\right)$} \\
\hline & $\begin{array}{l}\text { Keuntungan } \\
\text { Relatif }\end{array}$ & $\begin{array}{l}\text { Keselarasan/ } \\
\text { Kompatibilitas }\end{array}$ & $\begin{array}{c}\text { Kompleksitas/ } \\
\text { Kerumitan }\end{array}$ & $\begin{array}{l}\text { Trial } \\
\text { Ability/ } \\
\text { Dapat } \\
\text { Dicoba }\end{array}$ & $\begin{array}{l}\text { Observability/ } \\
\text { Dapat Diamati }\end{array}$ \\
\hline Kondisi Alam & $.623^{* *}$ & $.793^{* *}$ & $.846^{* *}$ & $.635^{* *}$ & $.699 * *$ \\
\hline $\begin{array}{l}\text { Interaksi } \\
\text { Sosial }\end{array}$ & $.368^{* *}$ & $.651^{* *}$ & $.511 * *$ & $.539 * *$ & $.537 * *$ \\
\hline Budaya & $.489 * *$ & $.699 * *$ & $.760^{* *}$ & $.568 * *$ & $.610^{* *}$ \\
\hline $\begin{array}{l}\text { Perilaku } \\
\text { Masyarakat }\end{array}$ & $.385^{*}$ & $.265^{*}$ & $.334 *$ & $.401 *$ & $.459 *$ \\
\hline $\begin{array}{l}\text { Kondisi } \\
\text { Ekonomi } \\
\end{array}$ & $.727^{* *}$ & $.761 * *$ & $.840 * *$ & $.690 * *$ & $.743 * *$ \\
\hline
\end{tabular}

Distribusi faktor perilaku masyarakat dibagi menjadi tiga kategori yaitu rendah, sedang dan tinggi. Kategori rendah dengan skor 1, kategori sedang dengan skor 2, sedangkan kategori tinggi dengan skor 3. Dari 40 responden sebanyak 24 persen menyatakan bahwa faktor perilaku masyarakat yang berhubungan dengan kondisi alam pesisir masih rendah, 13 persen menyatakan pada kategori sedang, dan selebihnya 3 persen menyatakan mempunyai kategori yang tinggi.

\section{Distribusi Faktor Kondisi Alam} Terhadap Lingkungan Pesisir

Distribusi faktor kondisi alam dibagi menjadi tiga kategori yaitu rendah, sedang dan tinggi. Kategori rendah dengan skor 1, kategori sedang dengan skor 2, sedangkan kategori tinggi dengan skor 3. Dari 40 orang responden sebanyak 53 persen menyatakan bahwa faktor kondisi alam yang berhubungan dengan kondisi alam pesisir masih rendah, 42 persen menyatakan pada kategori sedang, dan selebihnya 5 persen menyatakan mempunyai kategori yang tinggi.

Dari rekapitulasi distribusi faktor lingkungan pesisir di atas kemudian dilakukan analisis hubungan antara faktor lingkungan pesisir dengan persepsi terhadap lingkungan pesisir untuk mengetahui variabel mana saja yang berhubungan secara signifikan dengan persepsi nelayan terhadap lingkungan pesisir. Distribusi lingkungan pesisir terdiri dari variabel kondisi alam, interaksi sosial, budaya, perilaku masyarakat serta kondisi ekonomi. Setelah dilakukan analisis 
dengan menggunakan uji korelasi Rank Spearmen diketahui bahwa tingkat variabel faktor lingkungan pesisir yang sangat signifikan berhubungan dengan persepsi lingkungan pesisir adalah variabel kondisi alam, interaksi sosial, budaya dan kondisi ekonomi. Korelasi langsung ini ditunjukkan dengan besaran (rs) variabel kondisi alam terhadap persepsi lingkungan pesisir pada keuntungan relatif sebesar $.623^{* *}$, pada Keselarasan/ Kompatibilitas sebesar .793**, pada Kompleksitas/ Kerumitan sebesar .846**, pada Trial Ability/ Dapat Dicoba sebesar .635**, pada Observability/ Dapat Diamati sebesar $.699^{* *}$. Besaran (rs) variabel interaksi sosial terhadap persepsi lingkungan pesisir pada keuntungan relatif sebesar .368**, pada Keselarasan/ Kompatibilitas sebesar .651**, pada Kompleksitas/ Kerumitan sebesar $.511^{* *}$, pada Trial Ability/ Dapat Dicoba sebesar .539**, pada Observability/ Dapat Diamati sebesar .537**. Besaran (rs) variabel budaya terhadap persepsi lingkungan pesisir pada keuntungan relatif sebesar $.489^{* *}$, pada Keselarasan/ Kompatibilitas sebesar .699**, pada Kompleksitas/ Kerumitan sebesar .760**, pada Trial Ability/ Dapat Dicoba sebesar .727**, pada Observability/ Dapat Diamati sebesar .610**. Besaran (rs) variabel kondisi ekonomi terhadap persepsi lingkungan pesisir pada keuntungan relatif sebesar $.761^{* *}$, pada Keselarasan/ Kompatibilitas sebesar $.761^{* *}$, pada Kompleksitas/ Kerumitan sebesar $.840^{* *}$, pada Trial Ability/ Dapat Dicoba sebesar .690**, pada Observability/ Dapat Diamati sebesar.743**.

Disimpulkan bahwa karakteristik individu pelaku utama (nelayan) yang berhubungan nyata dan signifikan dengan persepsi terhadap lingkungan pesisir adalah tingkat kekosmopolitan pelaku utama (nelayan), sedangkan pada faktor lingkungan pesisir variabel yang berhubungan nyata adalah kondisi alam, interaksi sosial, budaya dan kondisi ekonomi.

\section{Kesimpulan}

a. Mayoritas pelaku utama (nelayan) dalam penelitian ini berumur dewasa muda (19-35) tahun, tingkat pendidikan formal rata-rata rendah (SD), pengalaman usaha rendah (1-5 tahun), dan tingkat kekosmopolitan yang sedang (skor 2).

b. Hasil analisis Rank Spearman pada taraf kepercayaan $\alpha=0,05$ menunjukkan bahwa karakteristik pelaku utama (nelayan) yang berhubungan nyata dengan persepsi 
lingkungan pesisir adalah variabel tingkat kekosmopolitan pelaku utama (nelayan), sedangkan pada faktor lingkungan pesisir variabel yang berhubungan nyata dengan persepsi lingkungan pesisir adalah kondisi alam, interaksi sosial, budaya dan kondisi ekonomi pelaku utama (nelayan).

c. Hasil hipotesis dari karakteristik nelayan menunjukkan bahwa tingkat kekosmopolitan pelaku utama (nelayan) berpengaruh signifikan terhadap keempat variabel persepsi lingkungan pesisir yaitu keuntungan relatif, keselarasan/ kompatibilitas, kompleksitas/ kerumitan, trial ability/ dapat dicoba serta observability/ dapat diamati, demikian juga dengan faktor lingkungan pesisir pada variabel kondisi alam, interaksi sosial, budaya dan kondisi ekonomi pelaku utama (nelayan) berpengaruh signifikan terhadap keempat variabel persepsi lingkungan pesisir.

\section{Saran}

a. Perlu adanya pendampingan dari lembaga penyuluhan setempat terutama serta Dinas Kelautan dan Perikanan terkait untuk mengimbangi mayoritas tingkat pendidikan pelaku utama (nelayan) yang masih rendah, terutama untuk pelatihan-pelatihan tentang keterampilan di bidang perikanan.

b. Diperlukan penelitian lebih lanjut mengenai pengaruh persepsi lingkungan masyarakat pesisir di daerah ini yang dominan sehingga dapat lebih meningkatkan penghasilan pelaku utama (nelayan).

\section{DAFTAR PUSTAKA}

Ali AB. 1998. Impact of fish introductions on indigenous fish population and fisheries in Malaysia. In: I.G. Cowx (editor): Stocking and introduction of fish. Fishing News Books, London, pp. $274-286$.

Allen GR. 1991. Field guide to the freshwater fishes of New Guinea. Christensen Research Institute, Madang - Papua New Guinea. $268 \mathrm{p}$.

Allen GR. 1998. A new genus and species of Rainbowfish (Melanotaeniidae) from fresh waters of Irian Jaya, Indonesia. Revue Française d'Aquariologie 25 (1-2): 11-16

Allen GR. 2001. A New Species of Rainbowfish (Glossolepis: Melanotaeniidae) from Irian Jaya, Indonesia. Fishes of Sahul, 15(3): 766-775

Allen GR, Hortle KG, Renyaan SJ. 2000. Freshwater fishes of the Timika region New Guinea. PT Freeport Indonesian Company, Timika. $175 \mathrm{p}$.

David Dudgeon, Angela H. Arthington, Mark O. Gessner, Zen-Khiro 
Kawabata, Duncan J. Knowler, Christian Leveque, Robert J. Naiman, Anne-Helene PrieurRichard, Doris Soto, Melanie L.J. Stiassny, Caroline A. Sulivan, 2006. Freshwater biodiversity: Importance, threats, status and conservation challenges. Biological Reviews, volume 81, issue 2, May 2006, Pages 163$182 . \quad$ e-mail: ddudgeon@hkucc.hku.hk

de Beaufort LF. 1940-1962. The fishes of the Indo-Australian Archipelago, vol. 8 - 11. E. J. Brill, Leiden.

Elvira B. 1998. Impact of introduced fish on the native freshwater fish fauna of Spain. In: Cowx IG (editor): Stocking and introduction of fish. Fishing News Books, London, pp. 186 190.

Froese R \& Pauly D. Editors. 2013. Fish Base. Worl Wide Web electronic publication. www.fishbase.org. version $(04 / 2013)$

Gorena M \& Ortal R. 1999. Biogeography, diversity and conservation of the inland water fish communities in Israel. Biological Conservation 89: 1 9

Gosset C, J. Rives, J. Labonne. 2006. Effect of habitat fragmentation on spawning migration of brown trout (Salmo trutta L.). Ecol. Freshw. Fish 2006: 15: 247-254

Hadiaty RK \& Siebert DJ, 1998. Two new species of Osteochilus (Teleostei: Cyprinidae) from Sungai Lembang, Suag Balimbing Research Station, Gunung Leuser National Park, Aceh, Northwestern Sumatra. Revue Francaise d'Aquariologie
Herpetologie Journal., 25 (1-2): 1-4

Hadiaty RK \& Siebert DJ. 2001. Nemacheilus tuberigum, a new species of loach (Teleostei: Balitoridae) from Aceh, northwestern Sumatra, Indonesia. Bull. Nat. Hist. Mus. Lond. (Zool.), 67 (2): 183-189

Hadiaty RK \& Wirjoatmodjo S. 2002. Studi pendahuluan biodiversitas dan distribusi ikan di Danau Matano, Sulawesi Selatan. Jurnal Iktiologi Indonesia 2 (2): 23 - 29

Haryono \& Tjakrawidjaja AH. 2004. The freshwater fishes of North Sulawesi. Bidang Zoologi Puslit Biologi LIPI, Bogor. 120 p.

Kartamihardja ES. 2007. Spektra ukuran biomassa plankton dan potensi pemanfaatannya bagi komunitas ikan di zona limnetik Waduk Ir. H. Djuanda, Jawa Barat. Disertasi. Sekolah Pascasarjana, IPB. 137 p.

Kottelat M, Whitten AJ, Kartikasari SN, Wirjoatmodjo S. 1993. Ikan air tawar Indonesia bagian barat dan Sulawesi. Periplus, Hongkong. $293 p+84$ plates.

Kottelat M \& Whitten T. 1996. Freshwater biodiversity in Asia with special reference to fish. World Bank Technical Paper $343,59 \mathrm{p}$.

Kottelat M, Britz R, Hui TH, Witte KE. 2005. Paedocypris, a new genus of Southeast Asian cyprinid fish with a remarkable sexual dimorphism, comprises the world's smallest vertebrate. Proceedings of the Royal Society: Biological Sciences: 1 - 5

Li S 2001. The impact of large reservoirs on fish biodiversity and fisheries 
in China. In: De Silva S.S. (ed.), Reservoir and Culture-Based Fisheries: Biology and Management. ACIAR Conference Proceedings 98, Canberra, Australia, pp. 22-28.

McAllister DE, Craig JF, Davidson N, Delany S, Seddon M. 2001. Biodiversity Impacts of Large Dams. IUCN, UNEP or UNF. 68 p.

Ng HH, Wirjoatmodjo S, Hadiaty RK. 2004. Kryptopterus piperatus, a new species of silurid catfish (Teleostei: Siluri-formes) from northern Sumatra. Ichthyol. Explor. Freshw. 15(1): 91-95

Nguyen TTT \& de Silva SS. 2006. Freshwater finfish biodiversity and conservation: an asian perspective. Biodiversity and Conservation 15:3543-3568

Page LM, Hadiaty RK, Lopez JA, Rachmatika I, Robins RH. 2007. Two new species of the Akysis variegatus species group (Siluriformes: Akysidae) from Southern Sumatra and a redescription of Akysis variegatus Bleeker, 1846. Copeia (2): 292-303

Peh KSH. 2010. Invasive species in Southeast Asia: the knowledge so far. Biodiversity Conservation, 19: 1083-1099

Rachmatika I. 2003. Fish fauna of the Gunung Halimun National Park, West Java. Biodiversity Conservation Project.126 p.

Roberts TR. 1989. The freshwater fishes of western Borneo (Kalimantan Barat, Indonesia). California Academy of Sciences. $210 \mathrm{p}$
Shoko APA, Ngowo RR, Waya RK. 2005. Deleterious effects of nonnative species introduced into Lake Victoria, East Africa. Naga, 28 (3 \& 4): $27-32$

Simanjuntak CPH; Rahardjo MF, Sukimin S. 2006. Iktiofauna di rawa banjiran Sungai Kampar Kiri. Jurnal Iktiologi Indonesia, 6 (2): $75-78$

Weber M \& de Beaufort LF. 1911-1936. The fishes of the Indo-Australian Archipelago, vol. 1 - 7. E. J. Brill, Leiden.

Welcomme, R.L. 1988. International introductions of inland aquatic species. FAO Fisheries Technical Paper, (294): 318 p.

Xie Y, Li Z, Gregg WP, Li D. 2001. Invasive species in China - an overview. Biodiversity and Conservation, 10: 1317-1341

David Dudgeon, Angela H. Arthington, Mark O. Gessner, Zen-Khiro Kawabata, Duncan J. Knowler, Christian Leveque, Robert J. Naiman, Anne-Helene PrieurRichard, Doris Soto, Melanie L.J. Stiassny, Caroline A. Sulivan, 2006. Freshwater biodiversity: Importance, threats, status and conservation challenges. Biological Reviews, volume 81, issue 2, May 2006, Pages 163182. e-mail: ddudgeon@hkucc.hku.hk 